\title{
Biodiversity of the endophytic fungi isolated from FCV tobacco grown in vertisols
}

\begin{abstract}
Tobacco grown in vertisols was investigated for endophytic Mycoflora as a possible source of bio protection to the host against insect pests, pathogens and even domestic herbivores. There are 65 Nicotiana sp. available in the world, of which 45 are being maintained in India. Several of these species have resistance to pests and diseases and are being used for developing disease/ pest resistant tobacco varieties. One hundred sixty segments from 30 plants of Nicotiana tabacum L. collected from different locations of FCV tobacco grown in vertisols were processed for the presence of endophytic fungi. A total of 9 fungal species viz. Aspergillus flavus, A. niger, Asperigillus sp, Penicillium sp. were isolated. Among the endophytic flora, Aspergillus was the most prominent genus.
\end{abstract}

Keywords: Aspergillus, endophytes, fungi, tobacco

\author{
Volume 8 Issue 6 - 2018
}

\author{
DV Subhashini \\ ICAR-Central Tobacco Research Institute, India
}

\begin{abstract}
Correspondence: DV Subhashini, ICAR-Central Tobacco Research Institute Rajahmundry-533 105,A.P, India, Email dv_subhashini@rediffmail.com
\end{abstract}

Received: October 20, 2018 | Published: December 19, 2018

\section{Introduction}

Endophytic fungi that live inside the tissues of living plants are under - explored group of microorganisms. ${ }^{1,2}$ reported endophytic bacteria from Nicotiana tabacum L. and their biocidal effect on plant pathogenic fungi. Estimated that there may be at least one million species of endophytic fungi alone. Recently they have received considerable attention after they were found to protect their host against insect pests, pathogens and even domestic herbivores. ${ }^{3}$ Almost all the plant species $(400,000)$ harbor one or more endophytic organisms. ${ }^{4}$ To date only a few plants have been extensively investigated for their endophytic biodiversity and their potential to produce bio-active secondary metabolites. Endophytic fungi generally live peacefully with their host, while these fungi under different conditions may act as facultative pathogen. One of the important roles of endophytic fungi is to initiate the biological degradation of dead or dying host-plant which is necessary for nutrient recycling. ${ }^{5}$ Such nutrient recycling helps in maintaining ecological balance. Charles and White $^{6}$ reported intercellular infections in certain plant species that lead to a symbiotic relationship between the host and its endophytic microbes, demonstrates the ability of many types of endosymbionts, acting as a unit with hosts to better survive, compete and reproduce. Practical applications of such endophytes are also discussed, for example, pharmaceutical developments and agricultural management. Dominance of fungi in the phyllosphere of tobacco and colonization patterns of fungi on different growth stages of tobacco leaves revealed that some fungi occurred at all stages while others restricted representation.

\section{Isolation of endophytic fungi from tobacco}

Stems and leaves of tobacco were sampled for the investigation of endophytic fungal communities. Healthy and mature plants were carefully chosen for sampling. Samples from different sites of each plant were randomly collected and brought to the laboratory in sterile bags and processed within few hours after the sampling to reduce the chances of contamination. Isolation of endophytic fungi was carried out according to the method described and the samples were rinsed gently in running water to remove dust and debris. After proper washing, stem sample were cut into long $0.5-1 \mathrm{~cm}$ pieces, whereas leaves were cut into $3-4 \mathrm{mmx} 0.5-1 \mathrm{~cm}$ pieces without any midrib under aseptic conditions. Surface sterilization was done by $1-13 \%$ sodium hypochlorite $(\mathrm{NaOCl})$ according to the type of tissues (for example higher concentration was used for leaf samples). Each set of plant material was treated with $75 \%$ ethanol for 1 min followed by immersion in sodium hypochlorite and again in $75 \%$ ethanol for 30 sec. Later the segments were rinsed three times with sterile distilled water. The plant pieces were blotted on sterile blotting paper. The efficiency of surface sterilization procedure was ascertained for every segment of tissue following the imprint method $^{8}$ In each petridish, 5-6 segments were placed on potato Dextrose Ager (PDA) supplemented

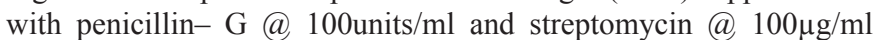
concentrations. The dishes were sealed with parafilm and incubated at $27^{\circ} \mathrm{C}+2^{\circ} \mathrm{C}$ for $4-6$ weeks in dark room. Fungi growing out of the plant segments were purified and identified after reference Tan and Zou, 2001).9 Species of Aspergillus and Penicillium were grown on PDA and Czapek's Dox agar for identification. Cultures were incubated and growth was examined daily during 6 weeks and colonizing frequency was calculated. ${ }^{10}$

Colonization frequency $(\%)=\frac{\text { No. of segments colonized by an endophyte }}{\text { Total no. of segments analyzed }} \times 100$

The plant materials were collected from Traditional Black Soils (TBS) growing tobacco. Sample (80 leaf samples and 80 stem samples) segments from 50 plants of tobacco were processed for the isolation of endophytic fungi. A total of 10 fungi belonging to species were isolated (Tables $1 \& 2$ ) which belong to the class Ascomycetes and Deuteromycetes. Most prominent endophyte in tobacco was found to be genus Aspergillus. Different species of Aspergillus were isolated and identified. Many fungi did not produce any reproductive structure, as they produced sterile mycelia and in some cases sterile pycnidium.

\section{Aspergillus flavus link}

Aspergillus flavus grew rapidly with floccosity when cultured on Czapek's Dox agar. It produced light greenish-yellow colour colony. Reverse side of the colonies were yellowish at primary stage of growth and brownish in mature age. Conidiophores arose from submerged hyphae, were $400-1000 x-15 \mu$ in size. Walls of conidiophores were pitted, rough and uncoloured. Conidial heads were hemispherical to subglobose. Vesicles were dome-like and $10-30 \mu$ in diameter. 
Sterigmata were mostly in two series. Single series sterigmata were also produced. Primary sterigmata were $7-10 \times 3-5 \mu$ and secondary sterigmata were $10-15 \times 2-5 \mu$ in size. Conidia were pyriform to almost globose, nearly colourless and varied in size between $2-4 \mu$.

Table I Endophytic fungi isolated from different parts of tobacco

\begin{tabular}{lll}
\hline Site of isolation & $\begin{array}{l}\text { Number of } \\
\text { samples }\end{array}$ & $\begin{array}{l}\text { Number of fungi } \\
\text { isolated }\end{array}$ \\
\hline Leaves & 80 & 12 \\
Stems & 80 & 8 \\
Total Number of Isolates & 160 & 20 \\
\hline
\end{tabular}

Table 2 Name and Colonizing frequency of Endophytic fungi isolated from tobacco

\begin{tabular}{llll}
\hline S. No. & Fungi & \multicolumn{2}{l}{$\%$ Frequency of colonization } \\
\hline & & Leaf & Stem \\
1 & Aspergillus flavus & 3 & 2 \\
2 & Aspergillus niger & 9 & 5 \\
3 & Aspergillus terreus & 7 & 4 \\
4 & Aspergillus sp. & 11 & 6 \\
5 & Penicillium sublateritium & 2 & 1 \\
6 & Penicillium sp & 5 & 2 \\
\hline
\end{tabular}

\section{Aspergillus niger van tieghem}

Aspergillus niger grew rapidly on Czapek's Dox agar. Colonies were carbon black in colour. It produced abundant submerged mycelia in the medium. Conidiophores were smooth with thick walls, unseptate, $300-800 \mu$ long and $6-10 \mu$ thick. They were uncoloured near the vesicle. Conidial heads were fuscous black, globose, up to $200-400 \mu$ in diameter. Vesicles were colourless and globose, thick walled up to $40 \mu$ in diameter. Conidial chains were present over the entire surface of vesicles. Conidia were rough, globose and $2-4 \mu$ in diameter.

\section{Penicillium sublateritium biourge}

Colonies of $P$. sublateritium were restricted when grown on Czapek's Dox agar. It reached $1-2 \mathrm{~cm}$ in diameter in 10 days at $27^{\circ} \mathrm{C}$. Colonies were velvety, orange-green in colour with thin white margin. Reverse side of the colony were pale orange. Mature colonies were deeply radiantly wrinkled. Spores were abundant with grey-green shades. Colonies did not produce odour and exudates. Conidiophores were mostly $70-80 \times 2 \mu$ in size and smooth walled. Phyloides were strictly monoverticillate, consisting of small verticels. Five to eight or ten parallel sterigmata were present on verticels. Sterigmata were mostly $10-15 \times 0.1-2.5 \mu$, occasionally $10 \mu$ in length. Spores arranged in chain. Conidial chains were up to $100 \mu$ long. The mature conidia were elliptical, smooth and 4.0-5.0 $\times 3.0 \mu$ in size. The endophytic fungi are one of the most unexplored and diverse group of organisms that make symbiotic associations with higher life forms and may produce beneficial substances for host. ${ }^{10,11}$ Endophytic organisms have received considerable attention after they were found to protect their host against insect pests, pathogens and even domestic herbivorous. ${ }^{10}$
However only a few plants have been studied for their endophyte biodiversity and their potential to produce bioactive compounds. Recently studies have been carried out about the endophytic bio diversity, taxonomy, reproduction, host ecology and their effort on host. ${ }^{5}$ Endophytes, are now considered as an outstanding source of bioactive natural products, because they occupy unique biological niches as they grow in so many unusual environments. ${ }^{12}$ A study of endophyte biodiversity of TBS tobacco was conducted by Subhashini et al., ${ }^{2}$ They have reported diversity of fungal species varying from 10 to 26 in the host. In the present study mainly Aspergillus, Penicillium were isolated as endophytic fungi.

\section{Acknowledgments}

None.

\section{Conflicts of interest}

The authors declared there is no conflicts of interest.

\section{References}

1. Akinloye AK, MO Abatan, O Alaka, et al. Histomorphometric and histopathological studies on the effect of Calotropis procera (Giant Milkweed) on the male reproductive organs of wistar rats. African Journal of Biomedical Research. 2002;5(1):1-2.

2. Subhashini DV, C Chandrasekara Rao, K Padmaja. Isolation and characterization of endophytic bacteria from Nicotiana tabacum L. and their biocidal effect on plant pathogenic fungi. Tob Res. 2009;35(1\& 2): $23-26$

3. Arnold AE, EA Herre. Canopy cover and leaf age affect colonization by tropical fungal endophytes: Ecological pattern and process in Theobroma cacao (Malvaceae). Mycologia. 2003;95(3):388-398.

4. Choedon T, G Mathan, S Arya, et al. Anticancer and cytotoxic properties of latex of Calotropis procera in a transgenic mouse model of hepatocellular carcinoma. World J Gastroenterol. 2006;12(16):2517-22.

5. Clay K, C Schardl. Evolution origins and ecological consequences of endophyte symbiosis with grasses. Am Nat. 2002; Suppl 4:S99-S127.

6. Charles W Bacon, James White. Microbial Endophytes, CRC Press: 2000 .

7. Subhashini DV, K Padmaja. Phyllosphere microfungi of FCV tobacco leaf. Tob Res.2010;36(1\&2): 100-102.

8. Suryanarayanan TS, G Venkatesan, TS Murali. Endophytic fungal communities in leaves of tropical forest trees: Diversity and distribution patterns. Cur Sci. 2003;85(4):489-492.

9. Tan RX, WX Zou. Endophytes: a rich source of functional metabolites Nat Prod Rep. 2001;18:448-459.

10. Weber J. A natural control of Dutch elm disease. Nature. 1981;292:449451 .

11. Shiomi HF, HSA Silva, IS De Melo, et al. Bioprospecting endophytic bacteria for biological control of coffee leaf rust. Sci Agric. 2006;63(1):32-39

12. Strobel G, B Daisy. Bioprospecting for microbial endophytes and their natural products. Microbiol. Microbiol Mol Biol Rev. 2003;67(4):491502. 